\title{
Anaerobic removal of linear alcohol ethoxylates
}

\author{
V. Mezzanotte ${ }^{\text {a,* }}$, E. Bolzacchini ${ }^{\text {a }}$, M. Orlandi ${ }^{\text {a }}$, A. Rozzi ${ }^{\text {b }}$, S. Rullo ${ }^{\text {c }}$ \\ a DISAT, Università degli Studi di Milano Bicocca, P.della Scienza, 1, 20126 Milano, Italy

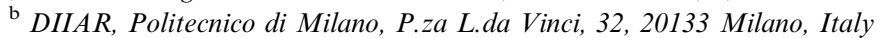 \\ ' IRSA-CNR, Via Occhiate, Brugherio (Milano), Italy
}

Received 23 August 2001; received in revised form 13 September 2001; accepted 17 September 2001

\begin{abstract}
The present paper deals with a laboratory-scale study of anaerobic treatment of two commercial mixtures (LS2, LT7) of alcohol ethoxylates with 8-14 carbon atoms and 2 and 7 ethoxy groups. Tests were carried out in batch, with a $2 \mathrm{~g} \mathrm{l}^{-1}$ single dose, and in semibatch, with daily $0.2 \mathrm{~g}^{-1}$ doses. The behaviour of the tested mixtures was different: anaerobic sludge adsorption was the main removal process for LS2, while adsorption was less significant and biodegradation was more important for LT7. These differences appeared to be mainly related to the ethoxy portion length determining the extent of biodegradability and adsorption. (C) 2002 Elsevier Science Ltd. All rights reserved.
\end{abstract}

Keywords: Wastewater treatment; Non-ionic surfactants; Linear alcohol ethoxylates; Anaerobic digestion; Biodegradation; Adsorption

\section{Introduction}

Linear alcohol ethoxylates (LAEs) belong to the chemical group of non-ionic surfactants (NISs) and are, commercially, the most significant. Their importance has grown over the last 10 years, with the widespread industrial use of NIS and in 1997 their production volume in Europe was estimated at more than 500000 ton (Reynolds et al., 1997). The lipophilic portion of these compounds is composed of an alkyl chain, while the polar hydrophilic portion is a polyethoxylated one. Their general formula is

$\mathrm{C}_{x} \mathrm{H}_{2 x+1}\left(\mathrm{OC}_{2} \mathrm{H}_{4}\right)_{n} \mathrm{OH}$

where $x$ is the number of alkyl chain carbon atoms and $n$ is the number of ethoxy units.

Changes in the number of carbon and ethoxy units in the molecule modify surfactant properties. In commercial and industrial products the number of carbon atoms in the alkyl chain and the number of ethoxy units range between 8 and 18 and between 1 and 20, respectively.

In principle, LAE, as other non-ionic surfactants, could be removed from wastewater by traditional

\footnotetext{
${ }^{*}$ Corresponding author. Tel.: +39-02-644-82795; fax: +39-02-64482736.

E-mail address: valeria.mezzanotte@unimib.it (V. Mezzanotte).
}

treatment processes such as biological oxidation or by advanced treatments such as ozonation (Belloli et al., 1997; Brambilla et al., 1993), activated carbon adsorption or monoreticulated resins (Rozzi et al., 2000). LAEs are degraded by hydrolysis of the ether linkage at the hydrophile-hydrophobe bond followed by oxidation of the two portions. Primary degradation may reach $99 \%$, according to screening test results (Reynolds et al., 1997). Ultimate degradation of non-ionic surfactants which undergo a high primary degradation, however, may be significantly lower (Reynolds et al., 1997). Semispecific analyses of non-ionic surfactants in treated effluents, as described by Standard Methods (APHA, AWWA, 1985), and by Tsubouchi et al. (1985), and used in most biodegradation tests (EEC Council Directive, 1982), are based on the formation of a complex between the polyethoxylated chain and an inorganic cation followed by the reaction of this complex with an anionic compound yielding a precipitated salt or a solvent-extractable coloured molecule. Therefore, they make possible the evaluation of the presence or absence of the ethoxylated group, but they cannot reveal other partial degradation pathways of the molecular structure (Marcomini, 1991). Moreover, a major drawback of semi-specific methods used for wastewater or mixed liquor analyses is the interference of other organic compounds. More complete information on intermediate degradation can only be drawn from COD or TOC 
analyses, which are often critical parameters for effluent discharge, and from the determination of by-products. In some cases, the removal of surfactants from wastewater is due to their adsorption on sludge, i.e. transfer from the liquid to the solid phase, but not due to biodegradation. Physical and chemical processes allow for a more efficient removal but their cost is often very high. Moreover, chemical oxidation frequently provides only an initial cleavage of the molecule but generates carbonylic by-products (Reynolds et al., 1997).

Anaerobic degradation has been reported for some LAEs (Reynolds et al., 1997). However, since any chemical transformation or separation of organic chemicals such as surfactants depends on their molecular structure, experimental results related to specific compounds cannot be generalized to the entire class of LAEs.

Many recalcitrant organic compounds, including some aromatic non-ionic surfactants, may be transformed by anaerobic co-metabolism with the addition of an easily degradable co-substrate acting as a carbon and energy source for microbial growth and maintenance and as an inducer of many co-metabolic enzymes and co-factors (Reynolds et al., 1997; Prats et al., 1997; Speece, 1996; Cheng et al., 1996, 1997).

The present paper reports the results of a laboratoryscale study on anaerobic treatment of selected alcohol ethoxylate mixtures with 8-14 carbon atoms and 1-7 ethoxy groups using milk whey as co-substrate.

\section{Methods}

\subsection{Surfactants and co-substrates}

Tests were performed on two commercial mixtures (Dehydol LT7 and LS2, produced by Henkel, Fino Mornasco, Como, Italy).

LT7 is an LAE commercial mixture composed of linear alcohols with varying carbon chain lengths and seven ethoxy groups. Its composition is: $48-58 \% \mathrm{C} 12 \mathrm{E} 7$, 18-24\% C14E7, 11-15\% C18E7, 0-3\% C10E7, 0-1\% C20E7.

Dehydol LS2 is composed of alcohols similar to the previous ones but with two ethoxy groups. The most important fraction $(70-75 \%)$ is made of C12E2. $24-30 \%$ of the mixture is composed of C14E2, while C10E2 and C16E2 are $0-2 \%$ each.

Dried defatted whey $(1 \mathrm{~g}$ whey $\cong 1 \mathrm{~g}$ COD $)$, supplied by Latteria Soresinese (Soresina, Italy), was used as cosubstrate in the reactor spiked with the surfactant, and was the sole organic carbon source in the blank. Whey was initially dissolved in hot water. Ethanol $(95 \%$ grade volume) was used to dissolve surfactants before spiking them into the reactors.

\subsection{Lab-scale plants}

The reactors had 4.51 volume, were stirred (30 rpm) and kept at $33{ }^{\circ} \mathrm{C}$ by a thermostated water jacket. They also had inlets for feed and outlets for supernatant (see later) and sludge. Methane production was measured as a function of the decreasing level of the liquid in the gas collecting column. Since the liquid was an alkaline solution $\left(\mathrm{NaOH} 0.1 \mathrm{M}\right.$ ) and reacted with $\mathrm{CO}_{2}$ and $\mathrm{H}_{2} \mathrm{~S}$, the gas volume within the column was only methane.

\subsection{Inocula}

The inoculum was composed of a 2:1 mixture of sludges coming from two full-scale anaerobic digesters. The first one was a conventional sludge at a treatment plant fed on mixed domestic and industrial sewage. The second one was a UASB fed on wastewater from a soft drinks factory. When the tests started, total solids in the reactors were about $15 \mathrm{~g} \mathrm{l}^{-1}$ and the average volatile suspended solids/total suspended solids ratio was 0.59 .

\subsection{Sampling and analyses}

Samples for COD analysis were collected daily from supernatants after settling the sludge in the reactors for $1 \mathrm{~h}$.

COD was determined according to Standard Methods (APHA, AWWA, 1985) after filtration (GF/C Whatman filters). Total solids and $\mathrm{pH}$ were also measured daily.

Methane volume was measured from the liquid level within the gas columns and corrected as $\mathrm{ml}$ in normal conditions $\left(1 \mathrm{~atm}, 0{ }^{\circ} \mathrm{C}\right)$.

Methane production rate $\left(r \mathrm{CH}_{4}\right)$ was calculated as the amount of methane produced/l reactor/day $(\mathrm{ml}$ $\left.1^{-1} \mathrm{~d}^{-1}\right)$.rCOD indicates the amount of COD converted to methane and was calculated from $r \mathrm{CH}_{4}$ on the basis of the stoichiometric relation $1 \mathrm{~g} \mathrm{COD}=0.35 \mathrm{~N}^{-\mathrm{CH}_{4}}$. Total and volatile solids were determined at the beginning and at the end of each test. Degradation by-products were identified by HPLC with evaporative light scattering detector (ELSD) 500 (Alltech). The instrument was a HPLC pump 600 E (Waters, Milford, MA, USA) equipped with a Reodyne 7125 injector with a 10 $\mu$ loop. The analytical column $(25 \mathrm{~cm} \times 2.1 \mathrm{~mm}$ ID $)$ used was a stainless-steel column packed with $5 \mu \mathrm{m}$ particles of silica-based $\mathrm{C} 8$ material, (Alltech). The mobile phase was a gradient of $\mathrm{CH}_{3} \mathrm{CN} / \mathrm{H}_{2} \mathrm{O}$ from $80 \%$ l $20 \%$ to $95 \% / 5 \%$ in $10 \mathrm{~min}$, and the flow was $0.2 \mathrm{ml} \mathrm{min}^{-1}$.

\subsection{Experimental procedures}

Anaerobic degradation of each tested mixture was evaluated daily as COD removal, by measuring COD in 
Table 1

Volumetric loading rate, $\mathrm{COD}$ measured in the liquid phase, and $\mathrm{CH}_{4}$ production rate $\left(r \mathrm{CH}_{4}\right)$ during the test with a sole dosage of LS2 mixture $(2 \mathrm{~g}$ $\left.1^{-1}\right)$

\begin{tabular}{|c|c|c|c|c|c|c|}
\hline \multirow[t]{2}{*}{ Day } & \multicolumn{4}{|c|}{ Volumetric loading rate $\left(\mathrm{mg} \mathrm{COD}^{-1} \mathrm{~d}^{-1}\right)$} & \multirow[t]{2}{*}{ Supernatant $^{\mathrm{a}} \mathrm{COD}\left(\mathrm{mg} \mathrm{l}^{-1}\right)$} & \multirow[t]{2}{*}{$r \mathrm{CH}_{4}{ }^{\mathrm{b}}\left(\mathrm{ml} \mathrm{l}^{-1} \mathrm{~d}^{-1}\right)$} \\
\hline & LS2 & $\mathrm{EtOH}$ & Whey & Total & & \\
\hline 0 & 4780 & 327 & 114 & 5221 & 347 & 159 \\
\hline 1 & 0 & 0 & 114 & 114 & 944 & 155 \\
\hline 2 & 0 & 0 & 114 & 114 & 900 & 163 \\
\hline 3 & 0 & 0 & 229 & 229 & 933 & 48 \\
\hline 4 & 0 & 0 & 0 & 0 & n.d. & 48 \\
\hline 5 & 0 & 0 & 0 & 0 & n.d. & 48 \\
\hline 6 & 0 & 0 & 114 & 114 & 968 & 40 \\
\hline 7 & 0 & 0 & 114 & 114 & 960 & 36 \\
\hline 8 & 0 & 0 & 114 & 114 & 850 & 21 \\
\hline 9 & 0 & 0 & 114 & 114 & 826 & 25 \\
\hline
\end{tabular}

n.d.: Not determined.

${ }^{a}$ See text, after sludge settling in reactor.

${ }^{\mathrm{b}}$ See text.

the supernatants and methane production. Each test was performed after adequate acclimation of sludge obtained by adding daily, for one week, small loads $(25 \mathrm{mg}$ $\mathrm{COD}^{-1}$ reactor) of the tested mixture plus whey (100 $\mathrm{mg} 1^{-1}$ reactor), as co-substrate, and ethanol, utilized to dissolve the surfactant. Every day mixing was stopped for $1 \mathrm{~h}$ prior to the addition of substrate and co-substrate and $300 \mathrm{ml}$ of supernatant were drawn from each reactor. A small amount $(40-50 \mathrm{ml})$ was used for analyses: whey and eventually ethanol + LAE were dissolved in the remaining supernatant which was made up with water to $300 \mathrm{ml}$ and subsequently re-injected into the digester to keep the working volume at 4.51 .

\subsection{Two kinds of tests}

Tests with a single dosage to monitor the LAE degradation and the by-products. The surfactant mixture was dissolved in ethanol and spiked into the reactor at the beginning of the test and subsequently whey was added daily (during week days) as co-substrate. On Fridays a double dosage was provided to supply each reactor for the week-end, during which time it was not fed. Methane yield for Saturdays, Sundays and Mondays is reported in tables as $1 / 3$ of the total week-end amount.

Semibatch (fill and draw) tests with daily LAE dosage to evaluate the removal of a mixture in semi-continuous input conditions. Co-substrate and surfactants, dissolved in ethanol, were added every day, except at weekends, as described above.

\section{Results and discussion}

\subsection{Tests adding $L S 2$}

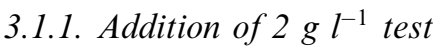

In Table 1 loading conditions and results are given as COD loading rate, COD in the supernatants and methane production rate, while Fig. 2 shows COD loads, COD trend in the supernatant (CODout) and the COD removal estimated on the basis of methane production ( $r \mathrm{COD})$.

The removal of LS2 was $84 \%$ one day after the addition and remained about the same (86\%) over 9 days. However, as can be seen in Fig. 1, adsorption seemed to play a more important role than biodegradation in the surfactant removal. Methane yield was consistent with co-substrate consumption and methane production rate decreased while the test progressed and was a little over $20 \mathrm{ml} / 1 \mathrm{reactor} /$ day at the end. After the 9-day test, the reactor was fed again with easily degradable substrate (whey). No toxic effect due to the surfactant was observed since the activity of methanogenic bacteria, as measured by COD removal and $\mathrm{CH}_{4}$ production, returned to normal levels. The significant role of adsorption was confirmed by HPLC analyses, performed on supernatant and on sludge samples collected immediately after the surfactant addition and during the following days. None of the characteristic peaks of LS2 could be observed in the supernatant samples while the peaks of C12E2 and of C14E2, which are the most im-

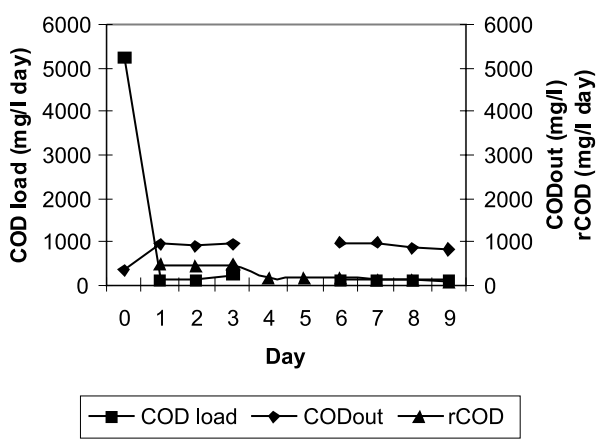

Fig. 1. COD loads (mg COD $\left.1^{-1} \mathrm{~d}^{-1}\right)$, COD in the supernatant (CODout, $\mathrm{mg}^{-1}$ ) and COD removed calculated on the basis of methane production $(r \mathrm{COD})$ during the test with a sole dosage of LS2 mixture $\left(2 \mathrm{~g} \mathrm{l}^{-1}\right)$. 


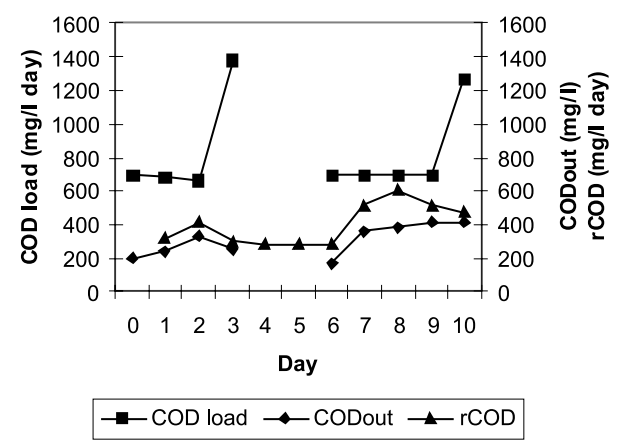

Fig. 2. COD loads (mg COD $1^{-1} \mathrm{~d}^{-1}$ ), COD in the supernatant (CODout, $\mathrm{mg}^{-1}$ ) and COD removed calculated on the basis of methane production $(r \mathrm{COD})$ during the $0.2 \mathrm{~g} \mathrm{l}^{-1} \mathrm{~d}^{-1}$ test with LS2.

portant compounds in LS2, were easily identified in the sludge extract, prepared by ethyl acetate.

\subsubsection{Addition of $0.2 \mathrm{gl}^{-1} d^{-1}$ test}

The results of this test (Fig. 2, Table 2) confirmed the low biodegradability of LS2 in anaerobic conditions: the

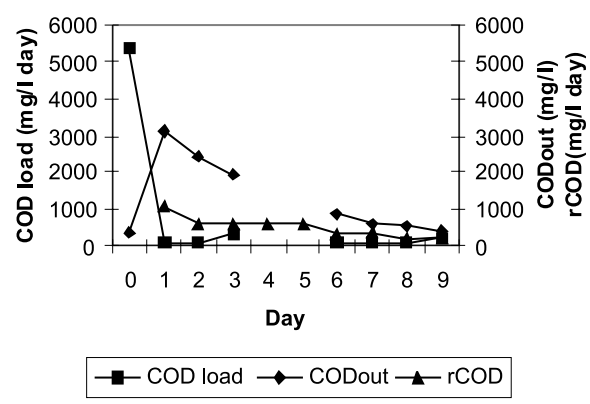

Fig. 3. COD loads ( $m g$ COD $\left.1^{-1} \mathrm{~d}^{-1}\right)$, COD in the supernatant (CODout, $\mathrm{mg}^{-1}$ ) and COD removed calculated on the basis of methane production $(r \mathrm{COD})$ during the test with a sole dosage of LT7 mixture $\left(2 \mathrm{~g}^{-1}\right)$.

supernatant COD gradually increased over time probably due to the accumulation of non-adsorbable and non-degradable residues or by-products of the added surfactants. The difference between COD removed from the liquid phase and COD converted to methane was invariably high. However, methane production rate and

Table 2

Volumetric loading rate, COD measured in the liquid phase, and $\mathrm{CH}_{4}$ production rate $\left(r \mathrm{CH}_{4}\right)$ during the LS2 test with daily dosage $\left(0.2 \mathrm{~g} 1^{-1} \mathrm{~d}^{-1}\right)$

\begin{tabular}{|c|c|c|c|c|c|c|}
\hline \multirow[t]{2}{*}{ Day } & \multicolumn{4}{|c|}{ Volumetric loading rate $\left(\mathrm{mg} \operatorname{COD~l}^{-1} \mathrm{~d}^{-1}\right)$} & \multirow[t]{2}{*}{ Supernatant ${ }^{\mathrm{a}}$ COD $\left(\mathrm{mg} \mathrm{l}^{-1}\right)$} & \multirow[t]{2}{*}{$r \mathrm{CH}_{4}{ }^{\mathrm{b}}\left(\mathrm{ml} \mathrm{l}^{-1} \mathrm{~d}^{-1}\right)$} \\
\hline & LS2 & $\mathrm{EtOH}$ & Whey & Total & & \\
\hline 0 & 478 & 103 & 114 & 695 & 198 & \\
\hline 1 & 478 & 91 & 114 & 683 & 242 & 113 \\
\hline 2 & 478 & 77 & 114 & 669 & 333 & 145 \\
\hline 3 & 956 & 190 & 228 & 1374 & 250 & 105 \\
\hline 4 & 0 & 0 & 0 & 0 & n.d. & 100 \\
\hline 5 & 0 & 0 & 0 & 0 & n.d. & 100 \\
\hline 6 & 478 & 98 & 114 & 690 & 169 & 100 \\
\hline 7 & 478 & 98 & 114 & 690 & 360 & 181 \\
\hline 8 & 478 & 98 & 114 & 690 & 384 & 210 \\
\hline 9 & 478 & 98 & 114 & 690 & 408 & 181 \\
\hline 10 & 956 & 200 & 114 & 1270 & 409 & 166 \\
\hline
\end{tabular}

n.d.: Not determined.

${ }^{a}$ See text, after sludge settling in reactor.

${ }^{\mathrm{b}}$ See text.

Table 3

Volumetric loading rate, $\mathrm{COD}$ measured in the liquid phase, and $\mathrm{CH}_{4}$ production rate $\left(r \mathrm{CH}_{4}\right)$ during the test with a sole dosage of LT7 $\left(2 \mathrm{~g}{ }^{-1}\right)$

\begin{tabular}{|c|c|c|c|c|c|c|}
\hline \multirow[t]{2}{*}{ Day } & \multicolumn{4}{|c|}{ 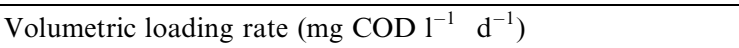 } & \multirow[t]{2}{*}{ Supernatant ${ }^{\mathrm{a}} \mathrm{COD}\left(\mathrm{mg} \mathrm{l}^{-1}\right)$} & \multirow[t]{2}{*}{$r \mathrm{CH}_{4}{ }^{\mathrm{b}}\left(\mathrm{ml} \mathrm{l}^{-1} \mathrm{~d}^{-1}\right)$} \\
\hline & LT7 & $\mathrm{EtOH}$ & Whey & Total & & \\
\hline 0 & 4900 & 331 & 114 & 5345 & 352 & \\
\hline 1 & 0 & 0 & 114 & 114 & 3134 & 362 \\
\hline 2 & 0 & 0 & 114 & 114 & 2409 & 214 \\
\hline 3 & 0 & 0 & 343 & 343 & 1915 & 202 \\
\hline 4 & 0 & 0 & 0 & 0 & n.d. & 202 \\
\hline 5 & 0 & 0 & 0 & 0 & n.d. & 202 \\
\hline 6 & 0 & 0 & 114 & 114 & 851 & 109 \\
\hline 7 & 0 & 0 & 114 & 114 & 585 & 135 \\
\hline 8 & 0 & 0 & 114 & 114 & 532 & 65 \\
\hline 9 & 0 & 0 & 237 & 237 & 394 & 80 \\
\hline
\end{tabular}

n.d.: Not determined.

${ }^{\text {a }}$ See text, after sludge settling in reactor.

${ }^{\mathrm{b}}$ See text. 
Table 4

Volumetric loading rate, COD measured in the liquid phase, and $\mathrm{CH}_{4}$ production rate $\left(r \mathrm{CH}_{4}\right)$ during the LT7 test with daily dosage $\left(0.2 \mathrm{~g}^{-1} \mathrm{~d}^{-1}\right)$

\begin{tabular}{|c|c|c|c|c|c|c|}
\hline \multirow[t]{2}{*}{ Day } & \multicolumn{4}{|c|}{ Volumetric loading rate $\left(\mathrm{mg} \mathrm{COD} \mathrm{l}^{-1} \mathrm{~d}^{-1}\right)$} & \multirow[t]{2}{*}{ Supernatant $^{\mathrm{a}}$ COD $\left(\mathrm{mg} \mathrm{l}^{-1}\right)$} & \multirow[t]{2}{*}{$\mathrm{rCH}_{4}{ }^{\mathrm{b}}\left(\mathrm{ml} \mathrm{l}^{-1} \mathrm{~d}^{-1}\right)$} \\
\hline & LT7 & EtOH & Whey & Total & & \\
\hline 0 & 490 & 33 & 114 & 637 & 372 & \\
\hline 1 & 490 & 19 & 114 & 623 & 248 & 163 \\
\hline 2 & 490 & 41 & 114 & 645 & 213 & 157 \\
\hline 3 & 490 & 33 & 114 & 637 & 259 & 141 \\
\hline 4 & 980 & 67 & 228 & 1275 & 328 & 119 \\
\hline 5 & 0 & 0 & 0 & 0 & n.d. & 119 \\
\hline 6 & 0 & 0 & 0 & 0 & n.d. & 119 \\
\hline 7 & 490 & 29 & 114 & 633 & 226 & 130 \\
\hline 8 & 490 & 39 & 114 & 643 & 248 & 113 \\
\hline 9 & 490 & 19 & 114 & 623 & 198 & 145 \\
\hline
\end{tabular}

n.d.: Not determined.

${ }^{a}$ See text, after sludge settling in reactor.

${ }^{\mathrm{b}}$ See text.

COD removal from the liquid phase increased after the sixth day and during the last days the values of both parameters increased compared to those measured at the beginning of the test. This might well have indicated a partial adaptation of the microbial consortium.

\subsection{Tests adding $L T 7$}

\subsubsection{Addition of $2 \mathrm{gl}^{-1}$ test}

The second LAE mixture showed a somewhat different behaviour (Fig. 3 and Table 3): after the surfactant addition, the supernatant COD and methane production rate increased appreciably. Thereafter, COD decreased regularly as did methane production rate. Nevertheless, during the whole test, methane production was much higher than the one corresponding to the daily load, made only of the co-substrate. In fact, average $r$ COD was $160 \mathrm{ml} \mathrm{l}^{-1} \mathrm{~d}^{-1}$ while the value related only to the co-substrate load should have been $40 \mathrm{ml}$ $\mathrm{l}^{-1} \mathrm{~d}^{-1}$. After the third day methane yield, mainly related to co-substrate addition $\left(0.1 \mathrm{~g}^{-1} \mathrm{~d}^{-1}\right)$, was quite variable, ranging between 0.15 and $0.59 \mathrm{ml} \mathrm{CH}_{4} / \mathrm{mg}$ COD removed. The test average $(0.39 \mathrm{ml}$ per $\mathrm{mg}$ COD removed) was close to the stoichiometric value, confirming the active metabolism of anaerobic bacteria. The

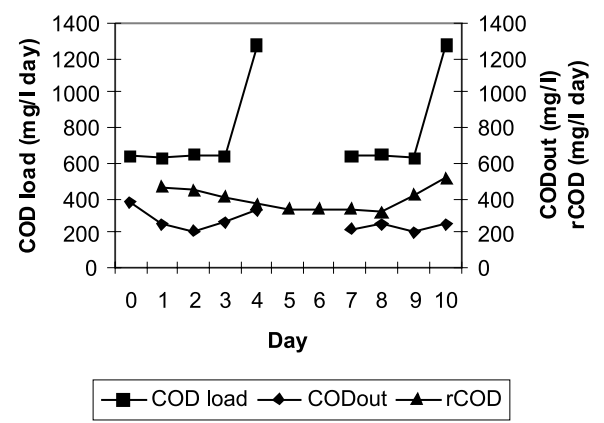

Fig. 4. COD loads (mg COD $1^{-1} \mathrm{~d}^{-1}$ ), COD in the supernatant (CODout, $\mathrm{mg}^{-1}$ ) and COD removed calculated on the basis of methane production $(r \mathrm{COD})$ during the $0.2 \mathrm{~g}^{-1}$ test with LT7. overall COD removal was $96 \%$. At the end of the test, there was a very good agreement between methane production and COD removed and COD concentration in the supernatant was about at the same level as before the surfactant addition, as indicated in Table 3.

\subsubsection{Addition of $0.2 \mathrm{gl}^{-1} d^{-1}$ test}

LT7 was well degraded also when it was added daily. The COD concentration in the supernatant remained fairly constant during the test, as reported in Table 4 and methane production, as $r \mathrm{COD}$, varied within a limited range as one may observe in Fig. 4.

\section{Conclusion}

Experimental results obtained in anaerobic degradation tests of two mixtures of linear alcohol ethoxylates indicate very different behaviours within the same class of compounds.

The two main factors, related to the water solubility or sludge adsorbability of the molecule, seem to be the number of carbon atoms in the alkyl chain and the number of ethoxy units in the hydrophilic portion.

As the most abundant compounds in both mixtures had similar carbon chain length, it may be assumed that the adsorption of the molecules on anaerobic sludge is inversely proportional to the number of ethoxy groups $(E)$. In fact, it was observed that for LS2 mixture $(E=2)$ removal took place mostly by adsorption, while the higher solubility of LT7 $(E=7)$ determined its different distributions between solid and liquid phases. The accepted assumption that microbial metabolism concerns first and foremost the ethoxy portion of the molecule (Reynolds et al., 1997) might also apply to anaerobic degradation and explain the different degradations observed for the two mixtures. Data from pulse and continuous addition tests indicate that the former technique is more suitable to discriminate adsorption and biode- 
gradation than the latter, which yields similar results for the two mixtures.

Last but not least, tests reported in the present work have been carried out using very high surfactant dosages, which are useful for research purposes, but are not found in real wastewaters. Therefore, the observed inhibition and toxicity effects in actual treatment plant conditions are expected to be much lower than the experimental results reported here.

In conclusion, anaerobic treatment might be considered as an interesting option to remove LAE surfactants from wastewaters both by degradation and by adsorption.

\section{References}

APHA, AWWA, WPCF, 1985. Standard Methods for the Analysis of Water and Wastewater, 16th ed.

Belloli, M., Bolzacchini, E., Guardavaglia, C., Meinardi, S., Mezzanotte, V., Orlandi, M., Rindone, B., Rozzi, A., 1997. Anaerobic treatment and ozonation of non ionic surfactants. In: 213th ACS National Meeting, San Francisco, CA, April, 13-17.

Brambilla, A.M., Calvosa, L., Monteverdi, A., Polesello, S., Rindone, B., 1993. Ozone oxidation of polyethoxilated alcohols. Water Research 27 (8), 1313-1322.

Cheng, J., Kanjo, Y., Suidan, M.T., Venosa, A.D., 1996. Anaerobic biotransformation of 2,4-dinitrotoluene with ethanol as primary substrate: mutual effect of the substrates on their biotransformation. Water Research 30 (2), 307-314.

Cheng, J., Suidan, M.T., Venosa, A.D., 1997. Kinetics of anaerobic cometabolism of 2,4-dinitrotoluene with ethanol as the primary substrate. Water Science and Technology 6-7, 271-278.

Council Directive 82/242/EEC of 31 March 1982 on the approximation of the laws of the Member States relating to methods of testing the biodegradability of nonionic surfactants and amending Directive 73/404/CEE. Official Journal No. L109 of 22.04.1982.

Marcomini, A., 1991. Evoluzione dei metodi di analisi dei tensioattivi in campioni ambientali e prescrizioni normative. La Rivista Italiana delle Sostanze Grasse LXVIII, 339-344.

Prats, D., Ruiz, F., Vazquez, B., Rodriguez-Pastor, M., 1997. Removal of anionic and non ionic surfactants in wastewater treatment plants with anaerobic digestion. A comparative study. Water Research 31 (8), 1925-1930.

Rozzi, A., Antonelli, M., Angeretti, C., Mantovani, R., Scaglia, E., 2000. Removal of non ionic surfactants used in tannery by an adsorbent resin. In: Proceedings of the CIWEM Conference Wastewater Treatment: Standards and Technologies to Meet the Challenge of the 21st Century, Leeds, UK, April, 4-6.

Reynolds, P.J., Young, W., Mascarenhas, R., 1997. Study on the possible problems for the aquatic environment related to surfactants in detergents. EEC Report No. EC 4294, 66 pp.

Tsubouchi, M., Yamasaki, N., Yanagisawa, K., 1985. Two-phase titration of poly(oxyethylene) nonionic surfactants with tetrakis (4-fluorophenyl)borate. Analytical Chemistry 57 (3), 783-784.

Speece, R.E., 1996. In: Speece, J.M. (Ed.), Anaerobic Biotechnology for Industrial Wastewaters. Archae Press, Nashville, TN, USA. 